\title{
Generation of three-dimensional prototype models based on cone beam computed tomography
}

\author{
J. Th. Lambrecht • D. C. Berndt • R. Schumacher • \\ M. Zehnder
}

Received: 28 May 2008 / Accepted: 23 September 2008 / Published online: 15 November 2008 (C) CARS 2008

\begin{abstract}
Purpose The purpose of this study was to generate threedimensional models based on digital volumetric data that can be used in basic and advanced education.

Methods Four sets of digital volumetric data were established by cone beam computed tomography (CBCT) (Accuitomo, J. Morita, Kyoto, Japan). Datasets were exported as Dicom formats and imported into Mimics and Magic software programs to separate the different tissues such as nerve, tooth and bone. These data were transferred to a Polyjet 3D Printing machine (Eden 330, Object, Israel) to generate the models.

Results Three-dimensional prototype models of certain limited anatomical structures as acquired volumetrically were fabricated.

Conclusions Generating three-dimensional models based on $\mathrm{CBCT}$ datasets is possible. Automated routine fabrication of these models, with the given infrastructure, is too timeconsuming and therefore too expensive.
\end{abstract}

Keywords Cone beam computed tomography - Digital volume tomography $\cdot$ 3D models $\cdot$ Rapid prototyping

\section{Introduction}

The technology of three-dimensional prototype modeling based on CT or MRI data was introduced into oral and

J. Th. Lambrecht $(\varangle) \cdot$ D. C. Berndt $\cdot$ M. Zehnder

Department of Oral Surgery, University Hospital for Oral Surgery,

Oral Radiology and Oral Medicine, University of Basel,

Hebelstraße 3, 4056 Basel, Switzerland

e-mail: j-thomas.lambrecht@unibas.ch

R. Schumacher

School of Life Sciences, Institute for Medical and Analytical

Technologies, University of Applied Sciences Northwestern

Switzerland, Muttenz, Switzerland maxillofacial radiology and surgery over two decades ago Brix and Lambrecht [1] after Marsh and Vannier [2] had reconstructed the "third dimension" of sequences of highresolution axial CT scans with algorithms. The models were used to plan and simulate maxillo-craniofacial surgery in three dimensions [3] and could be milled from a variety of materials. Laser-hardened acrylic resin had been shown to be a useful alternative $[4,5]$.

Cone beam computed tomography (CBCT) was introduced as a high-resolution imaging procedure in oral and maxillofacial radiology. Cone beam CT technology has a twodimensional sensor and uses a cone-shaped X-ray beam in place of a fan-shaped beam (CT). Volume data can be acquired in a single $360^{\circ}$ rotation of beam and sensor around the skull $[6,7]$. The characteristics of CBCT are lower entrance doses and higher resolution in the axial direction compared with conventional CT [8-10].

Nowadays individual medical models are routinely generated by rapid prototyping. Physical models are produced by selectively solidifying UV-sensitive liquid resin using a laser beam. The technology was first introduced in mechanical engineering and has also attracted a great deal of attention in clinical dentistry $[11,12]$. The aim of this study was to produce three-dimensional individual patient prototype models out of CBCT datasets that could eventually be used in basic and advanced education.

\section{Materials and methods}

Generating data

Different datasets of four patients were established by 3D CBCT (Accuitomo, J. Morita, Kyoto, Japan). One dataset is used as an example in this study. The imaging volume was 
a cylinder measuring $40 \mathrm{~mm}$ (diameter) $\times 30 \mathrm{~mm}$ (height) at the X-ray rotational center. Images were taken under the exposure conditions of $75-80 \mathrm{kV}$ and $4-6 \mathrm{~mA}$, which are the standard parameters and were changed for different subjects. The cone beam technique involves a single $360^{\circ}$ scan in which the X-ray source and a reciprocating area detector synchronously move around the patient's head. The top of the cone is the source of radiation and the bottom of the cone is the sensor, an image intensifier with a CCD camera. Within $17 \mathrm{~s}$ the region of interest is scanned in a total of 512 frames of two-dimensional images; these were recorded as an ".avi" format file.

i-Dixel

The Accuitomo software (i-Dixel images) calculates a volumetric dataset from 512 single digital images. Out of this dataset the single slices are calculated from within a volume of $3 \times 4 \mathrm{~cm}$ by selecting them in Dicom with a voxel volume of $0.125 \mathrm{~mm} \times 0.125 \mathrm{~mm} \times 0.125 \mathrm{~mm}$.

\section{Mimics}

The dataset is imported with a slice thickness of $0.5 \mathrm{~mm}$ into the planning software MIMICS (Materialise's Interactive Medical Image Control System, Materialise, Belgium). MIMICS is a link between the scanner data (CT, MRT, $\mathrm{CBCT}$ ) and a simple virtual 3D representation.

To work with the data, a so-called "mask" is generated. The threshold is necessary to create a first separation of the single anatomical structures (tooth, bone, nerve). A mask is generated for each structure and makes it possible to proceed within the work flow. The masks can be edited slice by slice by simply adding or removing voxels manually. Bone, teeth and soft tissue were separated using the above-mentioned functions. The masks can be exported as an STL data representation, which is a simple triangulated 3D surface dataset (Table 1).

\section{Magics}

The acquired 3D data can be imported as an STL dataset. Since the major part in the previous process was edited manually, the resulting surface of the anatomical structures was relatively rough. For this reason, a remesh was performed. The triangulated surface was smoothened and the edges of the triangles were assimilated. Using booling operations, figures without overlaps can be generated. These smoothened data were reimported into MIMICS as an STL dataset.
Table 1 Chart showing the workflow

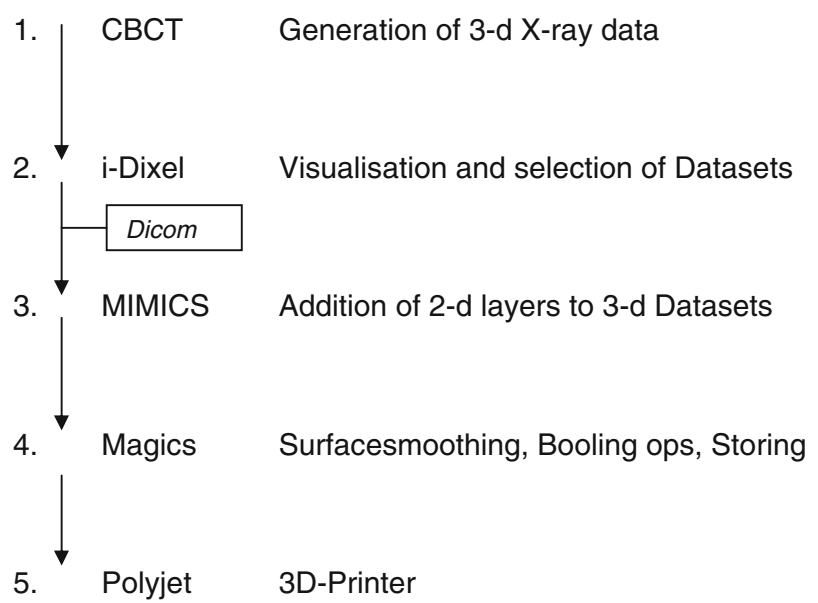

Polyjet 3D printing

Three-dimensional models are produced by the Polyjet method (Objet EDEN 250). Prototypes with high resolution and excellent surface quality can be produced layer by layer. Figure 1 shows the Polyjet rapid prototype fabrication system. The high resolution and good surfaces (without "stare steps") are acquired because of the layer thickness of $0.016 \mathrm{~mm}$.

UV-sensitive resins are added using printheads in extremely thin layers. Adding UV hardens the photopolymer. In the same process, supporting material is added that has a gel character and can be removed by water jet at the end of the construction process.

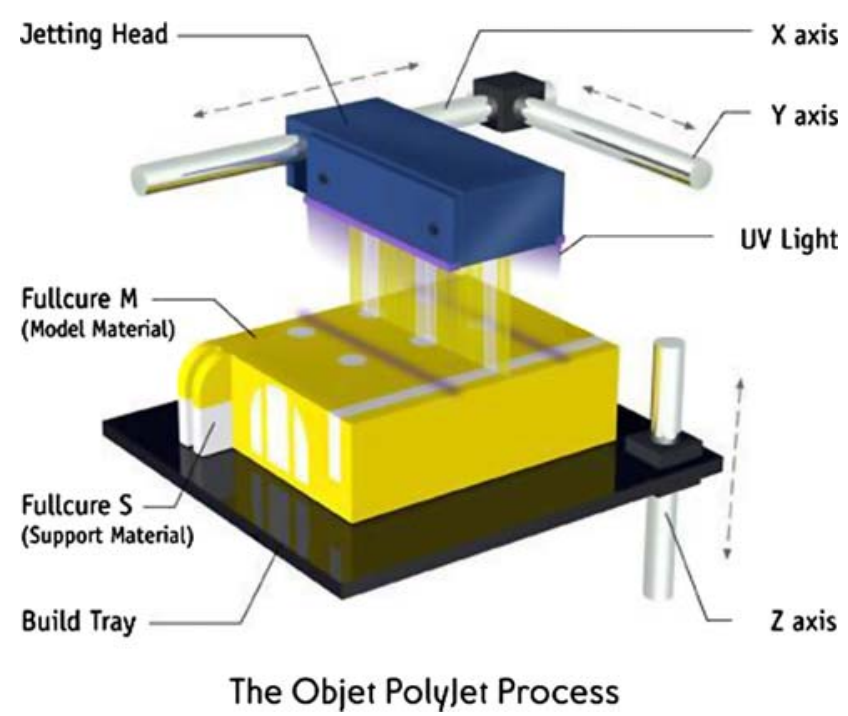

Fig. 1 The polyjet rapid prototype fabrication system showing the three axis movement of the components (OBJET, Israel) 


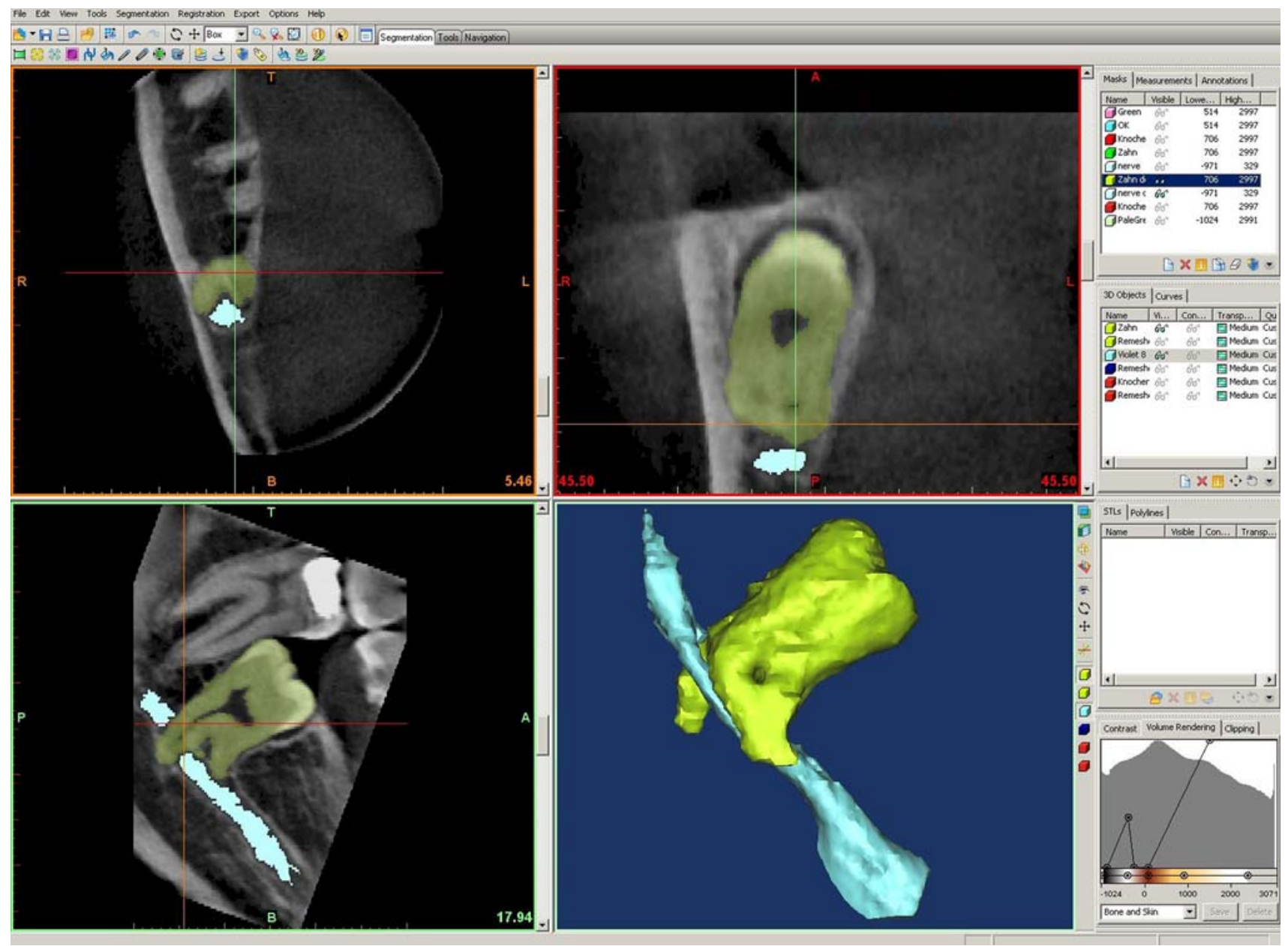

Fig. 2 The MIMICS software platform showing the 2D axial (upper left) coronal (upper right) and sagittal (lower left) dimensions with a mask for the gray values of the of the nervus alveolaris inferior (light

\section{Results}

The MIMICS software uses segmentation algorithms to obtain a $3 \mathrm{D}$ visualization at the end. The data which were acquired by i-Dixel can be read into MIMICS and are ready to be viewed in axial, sagittal and coronal dimensions.

The "reslice project" function makes it possible for the user to change the direction of the slice axes. A correct direction of axis simplifies later use of the data. The "threshold" function enables the user to tell the computer the gray value within the grayscale from which the program should detect and colour the voxels (Fig. 2).

The Magics software enables the user to smoothen the manually worked out MIMICS data (Figs. 3, 4).

Each generated structure of tooth, nerve and bone was separately produced as a model by the Polyjet method (Figs. 5, 6).

Thus fabrication of three-dimensional models based on $\mathrm{CBCT}$ data is possible. Featuring separate representation of blue). The 3D visualization of the three rendered masks shows the impacted wisdom tooth in close anatomical relation to the alveolar nerve (lower right)

hard and soft tissue enables the user to realize topographic relations of anatomic structures.

\section{Discussion}

Conventional CT has been the appropriate technology of choice for acquiring datasets in order to fabricate threedimensional models [13]. The disadvantages are space requirements, relatively high doses and high costs [14].

By comparison, CBCT, which is nowadays available for dento- maxillo-facial radiological units, requires less space, lower radiation doses, lower costs and offers a higher resolution than CT images [15-18]. The latter is due to the voxel size of the system used. Of course, voxel size is also crucial for accuracy. Studies on accuracy were done with various CBCT machines for implants [19] and human skulls and cadavers for the purpose of cephalometric measurements 


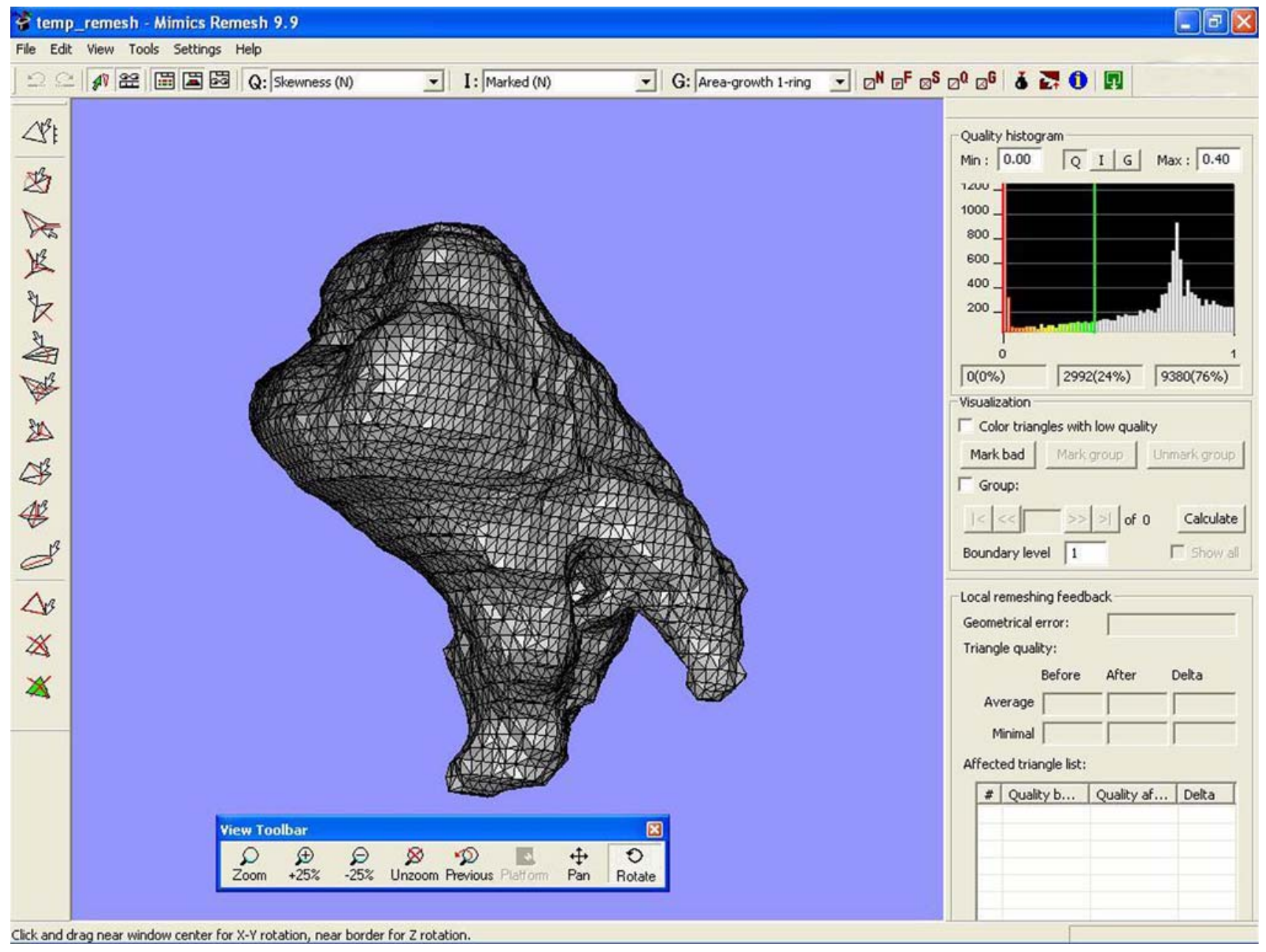

Fig. 3 Magics representation of a rough surface wisdom tooth

[20,21]. With regard to CBCT accuracy with Accuitomo, there is one report by Loubele et al. [22] yielding submillimeter accuracy for linear measurements on an ex vivo specimen. These results provide the basis for creating haptic models with adequate accuracy.

Artefact reduction is relevant to creating acceptable models [23]. Contrary to CT, CBCT does not provide readouts in Hounsfield Units (HU). The HU is the standard scale for measuring conventional $\mathrm{CT}$ values and was the basic platform for acquiring 3D models where defined tissues could be extracted because of their different HU. Mah and McDavic [24] suggest exporting CBCT data as a raw DICOM dataset and transferring the dataset to UTHSCSA Image Tool for analysis. Another method described showed that the attenuation coefficient of the test material in the phantom was determined with less than one per cent error. This sounds promising for the future and should be the subject of further research.
A grayscale is so far available in our set-up. With the MIMICS software program the aim was to extract certain gray values which were representative of a specific tissue, for example to discriminate soft tissue (nerve) from hard tissue (bone). To get the real 2D profile of the different tissues it was necessary to check every slice manually. Thus the separation of tissues layer by layer became very time-consuming. In the final stage individual patient datasets could be visualized. The computer-generated results provided a sufficient basis for rapid prototyping [25].

The use of three-dimensional reconstructions to evaluate the anatomic relationship of the mandibular canal and impacted mandibular third molars has recently been demonstrated by Friedland et al. [26].

The technique used in the present study goes one step further and seems to be highly suitable for creating haptic models to demonstrate complex anatomic situations, instructing students and planning operations. This technique 


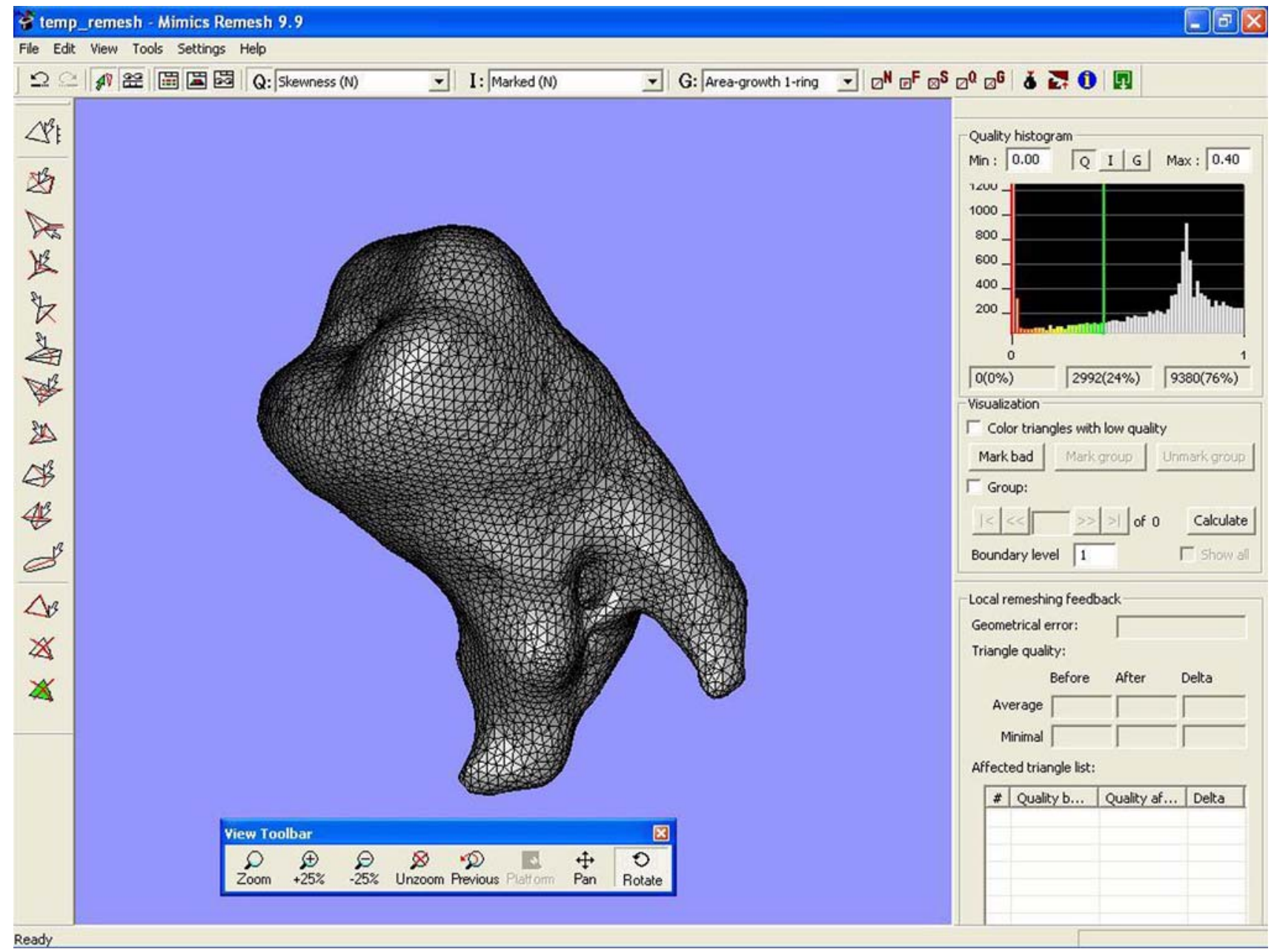

Fig. 4 Magics representation after smoothing of the data set shown in Fig. 3

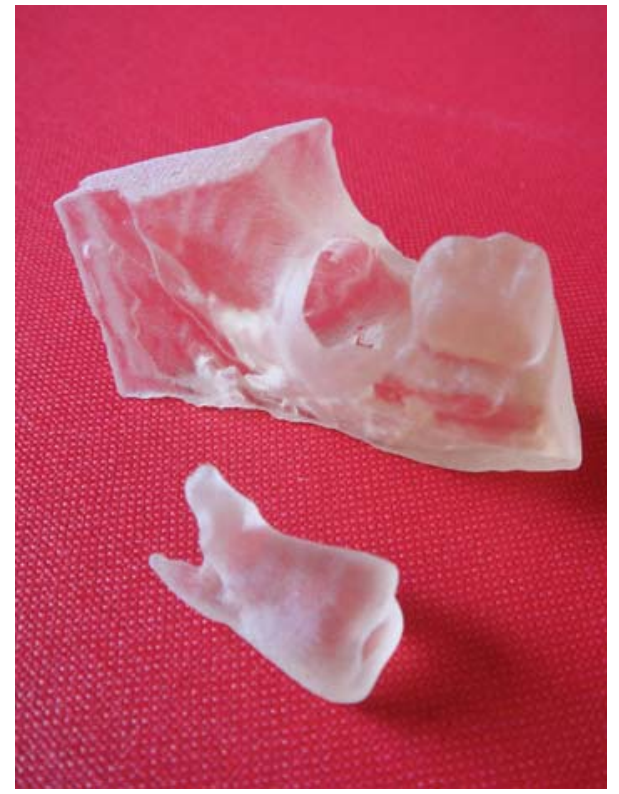

Fig. 5 3D models of a segmental piece of the mandible and the wisdom tooth according to the $\mathrm{CBCT}$ dataset

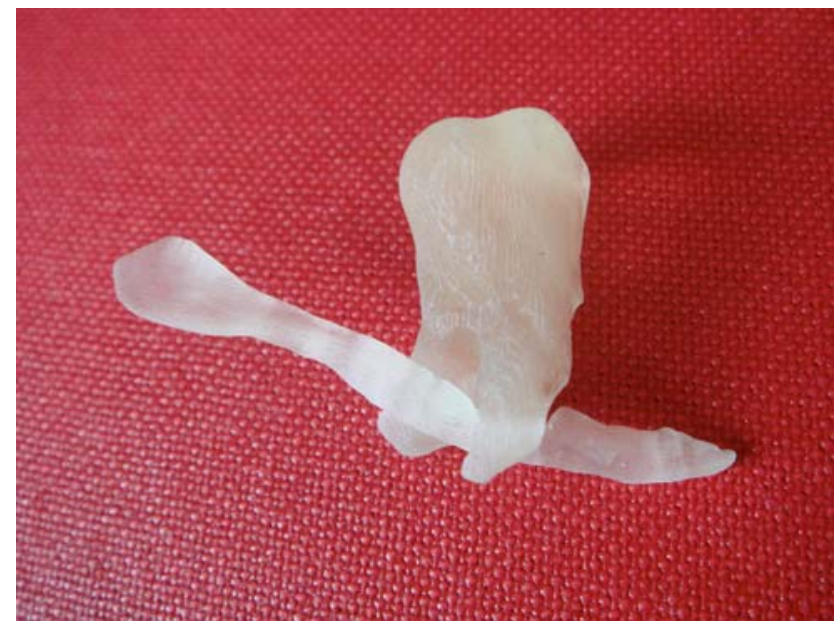

Fig. 63 D models of the wisdom tooth in close anatomical relationship to the nervus alveolaris inferior according to the CBCT dataset shown in a mechanical composition for demonstration 
could also be used in performing certain dento-alveolar operations. The disadvantage for the time being is a lack of cost-effectiveness because of the time-consuming procedure. These problems have to be solved before series for basic and advanced education can be produced.

\section{Conclusion}

To the best of the authors' knowledge, this is the first report on generating three-dimensional models based on CBCT datasets. It may become a useful technique for demonstration, planning and teaching, but other options for processing the datasets and producing models will need to be studied. The ultimate aim will be to use these models as a matter of routine in basic and advanced education, being comparable to conventional CT/MRI-based models.

\section{References}

1. Brix F, Lambrecht JTh (1987) Individuelle Schädelmodellherstellung auf der Grundlage computertomographischer Informationen. In: Schwenzer N, Pfeifer G (eds) Bildgebendes Untersuchungsverfahren in der Mund-, Kiefer- und GesichtsChirurgie, Band XXXII. Thieme Verlag Stuttgart, New York, pp 74-77

2. Marsh JL, Vannier MW (1993) The "third" dimension in craniofacial surgery. Plast Reconstr Surg 71:759-767

3. Lambrecht JT, Brix F (1990) Individual skull model fabrication for craniofacial surgery. Cleft Palate J 27:382-385

4. Lambrecht JTh, Hammer B, Jacob AL, Schiel H, Hunziker M, Kreusch T, Kliegis U (1995) Individual model fabrication in maxillofacial radiology. Dentomaxillofac Radiol 24:147-157

5. Petzold R, Zeilhofer HF, Kalender WA (1999) Rapid prototyping technology in medicine-basics and applications. Comput Med Imaging Graph 23:277-284

6. Toyofuku F, Konishi K, Kanda S (1986) Representation of arbitrarily curved sections of dentomaxillofacial region by the X-ray video CT. Oral Radiol 2:9-13

7. Bianchi SD, Lojacono A (1998) 2D and 3D images generated by cone beam computed tomography (CBCT) for dentomaxillofacial investigations. In: Lembke HU, Vannier M, Inamuson K, Forman A (eds) CARS computer assited radiology and surgery. Elsevier, Amsterdam pp 792-797

8. Honda K, Hashimoto K, Arai Y (1998) Clinical experience with ortho-CT for giagnosis of the temporomandibular joint disorders. Dentomaxillofac Radiol 27(Suppl 1):39

9. Iwai K, Arai Y, Nishizawa K, Tammisalo E, Hashimoto K, Shinoda K (1998) Estimation of radiation doses from ortho cubic super high resolution CT. Dentomaxillofac Radiol 27(Suppl 1):39

10. Arai Y, Tammisalo E, Iwai K, Hashimoto K, Shinoda K (1999) Developement of a compact computed tomographic apparatus for dental use. Dentomaxillofac Radiol 28:245-248

11. Lee SJ, Jung IY, Lee CY, Choi SY, Kum KY (2001) Clinical application of computer-aided rapid prototyping for tooth transplantation. Dental Traumatol 17:114-119
12. Choi JY, Choi JH, Kim NK, Kim Y, Lee JK, Kim MK, Lee JH, Kim MJ (2002) Analysis of errors in medical rapid prototyping models. Int J Oral Maxillofac Surg 31:23-32

13. Lambrecht JTh (1995) 3D-modeling technology in oral and maxillofacial surgery. Hauser, München

14. Vannier MW, Hildebolt CF, Conover G, Knapp RH, Crothers NY, Wang G (1997) Three-dimensional dental imaging by spiral CT. Oral Surg Oral Med Oral Pathol 84:561-570

15. Lemkamp M, Filippi A, Berndt D, Lambrecht JTh (2006) Diagnostische Möglichkeiten der digitalen Volumentomographie. Schweiz Monatsschr Zahnmed 116:645-653

16. Scarfe W, Farman A, Surkovic P (2006) Clinical application of cone-beam computed tomography in dental practice. J Can Dent Assoc 72:75-80

17. Arai Y, Honda K, Iwai K, Shinoda K (2001) Practical model "3DX" of limited cone-beam X-ray CT for dental use. Int Congr Ser 1230:713-718

18. Mozzo P, Procaci C, Tacconi A, Tinazzi Martini P, Gergamo Andreis I (1998) A new volumetric CT machine for dental imaging based in cone-beam technique: preliminiary results. Eur Radiol $8: 1558-1564$

19. Naitoh M, Kubota Y, Katsumata A, Ohsaki C, Ariji E (2006) Dimensional accuracy of a binder jet model produced from computerized tomography data for dental implants. J Oral Implantol 32:273-276

20. Periago DR, Scarfe WC, Moshiri M, Scheetz JP, Silveira AM, Farman AG (2008) Linear accuracy and reliability of cone beam CT derived 3-dimensional images constructed using an orthodontic volumetric rendering program. Angle Orthod 78:387-395

21. Veyre-Goulet S, Fortin T, Thierry A (2008) Accuracy of linear measurement provided by cone beam computed tomography to assess bone quantitiy in the posterior maxilla: a human caldaver study. Clin Implant Dent Relat Res (Epub ahead of print, accessed April 1 2008)

22. Loubele M, Van Assche N, Carpentier K, Maes F, Jacobs R, van Steenberghe D, Suetens P (2008) Comparative localized linear accuracy of small-field cone-beam CT and multislice CT for alveolar bone measurements. Oral Surg Oral Med Oral Pathol Oral Radiol Endod 105:512-518

23. Schulze D, Heiland M, Blake F, Rother U, Schmelzle R (2005) Evaluation of quality reformatted images from two cone-beam computed tomographic systems. J Craniomaxillofac Surg 33:19_ 23

24. Mah P, McDavid WD (2008) Conversion of CBCT gray levels to HOUNSFIELD units. Oral Surg Oral Med Oral Pathol. In: Selected abstracts from the 58th annual scientific session of the American academy of oral and maxillofacial radiology, Chicago, November 28-December 2, 2007; online accessed April 2008

25. Markl M, Schumacher R, Kuffer J, Bley TA, Henning J (2005) Rapid vessel prototyping: vascular modlin using 3t magnsetic resonance angiography and rapid prototyping technology. MAGMA $18: 288-292$

26. Friedland B, Donoff B, Dodson TB (2008) The use of 3-dimensional reconstructions to evaluate the anatomic relationship of the mandibular canal and impacted mandibular third molars. J Oral Maxillofac Surg 66:1678-1685 